\title{
Effect of Aerobic Regular Exercise Training on Blood Pressure Control for Patients with Hypertension
}

\author{
Mervat Abdel Fattah*, Hanan Gabert, Aida Elgamil*, Fatma Abo Elaninł
}

\begin{abstract}
Background: Hypertension affects over $26.3 \%$ of the Egyptian population and is considered one of the most significant risk factors for morbidity and mortality from coronary heart disease, chronic renal failure, and stroke. Lifestyle modification especially physical exercise is a mainstay in the management of blood pressure control. Objective: We sought to assess the effect of graded walking exercise on blood pressure in hypertensive patients Methods: Our study comprised 40 hypertensive patients with mild to moderate hypertension divided into 2 equal groups. Group I (experimental group) patients were given pharmacological medications and encouraged to graded walking exercise program and followed-up by the researchers over a period of eight weeks. Group II (control group) patients were given standard pharmacological medications only. Results: The results showed insignificant difference between $\mathrm{Gl}$ and GII in their weight and BMI on $2^{\text {nd }}, 6^{\text {th }}$, and $8^{\text {th }}$ weeks comparing with $1^{\text {st }}$ week. A non-significant improvement between Gl and Gll was found in heart rate as a short term effects through walking exercises. $(t=2.03, p=0.05)$. Comparing between group I and group II regarding the benefits of walking program exercises on heart rate, systolic, and, diastolic blood pressure; a statistical significant difference was observed on $4^{\text {th }}, 6^{\text {th }}$, and $8^{\text {th }}$ weeks in relation to heart rate $(p$ value $=0.0001,0.005$, and 0.0001$)$, respectively, systolic blood pressure ( $p$ value $=0.0001,0.006$, and 0.0001 ), respectively, and diastolic blood pressure ( $p$ value $=0.009,0.024$, and 0.002 ) respectively. Conclusion: The results of the study strongly support the beneficial effect of aerobic regular exercise in reduction of systolic \& diastolic blood pressure and heart rate in hypertensive patients with pharmacologic treatment. Special attention should be paid to aerobic exercise for hypertensive patients and should be integral component of hypertension education program.
\end{abstract}

\section{INTRODUCTION}

Hypertension is a widespread health problem effecting approximately 1 billion people worldwide and 1 out of every 6 persons on earth ${ }^{(1,2)}$. In EGYPT, high blood pressure is prevailing among one cause of death, as well as other
$26.3 \%$ of the population ${ }^{(3)}$. The importance of treating this "silent killer" lies in its associated risk to cardiovascular disease, the number

\footnotetext{
${ }^{\star}$ Medical Surgical Nursing Department, Faculty of Nursing, Alexandria University,

+Medical Surgical Nursing Department, Faculty of Nursing, Banha University

¥Cardiology Unit, Faculty of Medicine, Alexandria University
} 
diseases including renal disease, for the prevention and treatment of stroke, heart failure, and peripheral hypertension recommend lifestyle artery disease ${ }^{(4,5)}$. modifications in the form of 'regular

Although hypertension is defined as aerobic exercise, as well as a reduction systolic blood pressure (SBP) equal to of dietary sodium intake, and weight and greater than 140 and/or diastolic loss.(9) blood pressure (DBP) equal to and Exercise as a lifestyle modification greater than $90 \mathrm{mmHg}$. The new referred to a non-pharmacological classification of "pre-hypertensive" (SBP therapy, It is beneficial to a wide variety 120-139 and DBP $80-89 \mathrm{mmHg}$ ) has of health conditions. Most experts been introduced to identify individuals consider walking one of the most who are at a higher risk of developing appropriate aerobic activities. It is hypertension, pointing out an important simple and requires no special skill, fact that hypertension is a modifiable risk setting, or equipment other than a good factor $(6,7)$ pair of shoes. ${ }^{(10)}$

However, recent hypertension Most exercise prescriptions for guidelines recommend treatment hypertensive patients include duration of targets of $140 / 85 \mathrm{mmHg}$ or below, 20-60 minutes of aerobic exercise international community based surveys performed 3-5 times a week ${ }^{(11)}$ Recent show that in many countries only a guidelines from the Department of Health minority of people treated for suggest that each individual should hypertension are controlled to these participate in minimum of $30 \mathrm{~min}$ of levels(8). Many national guidelines 
moderate intensity activity at least 5 days

a week. A frequency of three exercise sessions per week has been considered to be the minimal frequency for blood pressure reduction $^{(12)}$.

The beneficial effect of regular exercise in hypertension is not limited to reduction of systolic and diastolic blood pressure only, It has also been shown to reduce left ventricular hypertrophy, improve exercise capacity, and quality of life. $(3,14)$ When combined with dietary alterations, regular exercise causes reduction of oxidative stress, increases nitric oxide availability, and improves the overall metabolic profile.(15)

The responses to acute bouts of exercises are the physiological changes that occur within only a few exercise sessions, whereas the chronic and are sometimes measurable even adaptations are derived from the 12 hours later ${ }^{(4)}$ accumulation of several continuous exercise bouts over a period of time.(4)
A recent meta-analysis supports this chronic role being partially explained by a decreased systemic vascular resistance in which the autonomic nervous system and renin-angiotensin system are most likely the underlying regulatory mechanisms $^{(16)}$. Another factor contributing to this decrease in vascular resistance is the increase of nitric oxide production causing a vasodilatation in response to regular aerobic exercise. ${ }^{(4)}$

Regular exercise reduces blood pressure by increasing circulation to the muscles and skin, and widening the arteries. It also improves renal function, which contributes to the body's ability to regulate and eliminate excess fluids. These effects on blood pressure are immediate, after first exercise session, It is well documented that blood pressure reduction with medication 
significantly reduces cardiovascular risk.

But non-pharmacologic strategies for blood pressure reduction, including weight loss, dietary modification, and exercise, are also effective. Particularly when patients have mild to moderate hypertension, these strategies offer the possibility of reducing blood pressure and cardiovascular risk without any of the adverse side effects associated with medication. ${ }^{(17)}$

Of course, the effect of daily exercise on hypertension adds up. If patient exercises moderately every day, by the time pressure starts resuming its usual level again. Within four weeks, regular aerobic exercise can lower blood pressure readings by as much as 5-15 mmHg. ${ }^{(4)}$ Therefore, this study was done to examine the effect of aerobic regular exercise training on blood pressure control for patients with mild to moderate hypertension.
As a member of health care team the nurse is vitally concerned about hypertension. Early case finding is one of the roles of the nurse, the nurse should encourage patients to adhere to treatment regimen, monitoring blood pressure as well as lifestyle modification in order to facilitate long term control of hypertension

\section{AIM OF THE STUDY}

This study aimed at assessing the effects of a graded walking exercise program on reducing the blood pressure for hypertensive patients.

\section{MATERIAL AND METHOD}

\section{Setting:}

The study was carried out in hypertension out patient's clinics at the Main University Hospital.

\section{Subjects:}

The study sample was including 40 adult patients with mild to moderate hypertension; age ranged from 30-60 
years old. They receive It included patients' name, age, sex, antihypertensive drug since one year or level of education, socio-economic, and more. Exclusion criteria included marital status as well as the patients' patients with diabetes mellitus, compliance to their therapeutic regimen cerebrovascular disease, significant as following: duration of drugs intake, valvular disease, chronic obstructive drugs used, and their usual diet intake. lung disease, and history of heart Part II Follow-up parameters' failure, also patients receiving drugs assessment sheet that can raise blood pressure. The

This part included follow-up exclusion based on patients' history and parameters as the patients' condition physical examination by medical doctor. on

Subjects were divided into two equal walking exercises program such as:

groups namely 20 patients as -Patients' weight (wt.).

experimental group (GI) and 20 control -Basal Metabolic index (BMI).

group (GII). $\quad$-Heart rate $(H R)$.

Tools:

-Systolic Blood Pressure (SBP).

The tools of the study were including -And Diastolic Blood Pressure (DBP). the

2- Exercise Guide Sheet for the following:

Patients' Walking Program (EGSPWP)

1- Patient's screening sheet

This sheet comprised the time table This sheet comprised of two parts of for walking program per week and assessment: comfort during each walking session.

Part I demographic data and history METHOD 
1- A written approval was obtained from each time, patients' assessment the head of the assigned Medical Out parameter was measured.

Patient Department.

2- Study tools were developed based on thorough review of literature and researches in this field.

3. The informed consent was taken from patients who are eligible for the criteria after explanation of the study purpose.

4. Echo was done for all subjects in experimental group to exclude any patient who suffered from left ventricular hypertrophy.

5. All subjects are met five times, on the $1^{\text {st }}$ time demographic data were taken \& after that the height, body weight, heart rate, as well as systolic and diastolic blood pressure were measured to establish baseline data for subsequent evaluation

6. As regard control group, the researchers asked the patients to follow up on $2^{\text {nd }}, 4^{\text {th }}, 6^{\text {th }}$, and 8 th weeks. In
As regard the walking program for the experimental group, in the $1^{\text {st }}$ time the researchers asked the patients to walk 3 times a week for 10 minutes for next two weeks and follow-up outpatient clinic \& in the $2^{\text {nd }}$ time, the patients were asked to walk 3 times a week for 20 minutes for another next two weeks and follow-up outpatient clinic. The duration of walking exercise increased until it reached 40 minutes in the $4^{\text {th }}$ time follow-up.

7. In each time of follow-up, patients' assessment parameter was measured. Patients were instructed to walk the recommended time without stopping walk except in case if she/he felt dizziness, dyspnea, chest pain, or pain in her/his neck, arm, or shoulder during walking.

8. The researchers asked each subject in 
GI as regard their comfort about the duration which was spent on the exercises as means to assess their tolerance and condition with the limited duration and frequency.

\section{Statistical analysis:}

Data were analyzed using SPSS with chi-square used in qualitative data and student's t-test in analyzing quantitative data. The correlation between different parameters was done using Pearson's coefficient.

\section{RESULTS}

Table 1 showed that mean age of patients in the experimental group (GI) was $48.60 \pm 8.45$ years while it was $49.25 \pm 9.68$ years for those in the control group. Approximately all the studied sample of both groups (G1 \& G2) were female (95\% and 100\%), respectively ( $p$ value $=0.3112$ ). Ninety percent $(90 \%)$ of patients in the control group (GII) and $80 \%$ in the $=5.0, \mathrm{p}$ value $=0.01$. Seventy percent experimental group (GI) were illiterate and minority of both groups of GI \& GII can read and write (10\% and $20 \%)$, respectively. $(P$ value $=0.5175)$. Low socioeconomic status showed the highest frequency in the experimental and control groups (100\% and 95\%), respectively. $(P=0.3112)$. More than three quarters of the studied sample of both groups were married (80\%) p value $=1.000$.

Table 2 revealed that mean of duration of drugs intake in the experimental group was $4.39 \pm 2.89$ while, it was $7.53 \pm 7.65$ for control group (GII). On the other hand, the category of drugs used by both groups of experimental and control groups, was single drug used by $75 \%$ and $40 \%$ respectively. But combined drug was taken by $25 \%$ and $60 \%$, respectively so that, there was a significant difference $t$ 
of both experimental and control groups

were following the lower dietary salt. In relation to the lower dietary fat, the same percent $(70 \%)$ of experimental group were following it and $60 \%$ of control group $(t=0.0, p$ value $=1.000$ and $t=0.4395, p$ value $=0.5073)$, respectively.

Table 3 represented the differences between experimental and control groups regarding an effect of walking program on the follow-up parameters namely: weight, basal metabolic index, heart rate, and systolic and diastolic blood pressure, by comparing the 1st time as a baseline data with $2^{\text {nd }}, 4^{\text {th }}, 6^{\text {th }}$, and $8^{\text {th }}$ weeks.

Findings revealed that the mean difference between the experimental and control groups was almost similar before the beginning of walking program exercises (baseline data) in relation to all the follow-up parameters namely Wt, BMI, HR, SBP, and DBP ( $p$ value $=0.932,0.671,0.090,0.767$, and 0.849), respectively.

There was no statistical significant difference between $\mathrm{Gl}$ and GII as regard weight, and $\mathrm{BMI}$ on $2^{\text {nd }}, 4^{\text {th }}, 6^{\text {th }}$, and $8^{\text {th }}$ weeks compared with $1^{\text {st }}$ time as baseline data $(p$ value $=0981,0.758,0.565$, and $0.434),(p$ value $=0.621,0.848,0.927$ and 0.756$)$, and $(p$ value $=0.621,0.848$ and 0.927 ), respectively. It was found that there were slightly effects of exercise on BMI and body weight for the experimental groups. The inversely significant improvement between $\mathrm{Gl}$ and Gll was found only on $2^{\text {nd }}$ week in heart rate as short term effects through walking exercises. $(t=2.03, p=0.052)$.

Comparing between group I and group II regarding the benefits of walking program exercises on $\mathrm{HR}$, SBP, and DBP, it was found that there was a statistical significant difference 
on $4^{\text {th }}, 6^{\text {th }}$, and $8^{\text {th }}$ weeks in relation to heart rate $(p$ value $=0.00,0.005$, and 0.00), respectively, systolic blood pressure $(p$ value $=0.00,0.006$, and $0.00)$, respectively, and diastolic blood pressure $(p$ value $=0.009,0.024$, and 0.002), respectively.

Table 4 presents the patient's comfort as regard the duration spent on each walking session by group I. As regard the patient's comfort, it was found that $10 \%, 20 \%$, and $25 \%$ of studied subjects reported that they had discomfort during walking program at 20,30 , and 40 minutes, respectively. In relation to the degree of comfort this table also showed that the majority of the studied subjects $90 \%, 80 \%$, and $75 \%$ reported that they were comfort during 20,30 , and $40 \mathrm{~min}$ walking program, respectively.

\section{DISCUSSION}

Regular aerobic exercise is one of the most important steps for preventing and controlling high blood pressure. ${ }^{(18)}$

For patients whose hypertension is shown, over several weeks, to be mild to moderate (pressures less than 160/105 $\mathrm{mm} \mathrm{Hg}$ ), physicians usually suggest a 3month trial of lifestyle modification before initiating drug therapy. This trial includes, in addition to the exercise prescription, a diet low in salt, alcohol, and calories. Also, patients who smoke should be strongly urged to quit. ${ }^{(17)}$

As regards to exercise, unfortunately, exercise is not a common practice in Egyptian society although the beneficial aerobic regular exercise training on blood pressure control.

Regarding sex, an earlier metaanalysis of 25 clinical trails looked more closely at patient variables and found that both men and women benefited from aerobic exercise program, with the effect significantly greater in women than in 
men.(19) This finding is not observed in of exercise should be at least 30 minutes the present study as a result of the small per day; this can be achieved in one number of male patients in relation to continuous session, or, a sum total of female patients.

smaller periods of exercise throughout

The present study found a the day(6). This recommendation significant reduction of systolic and supported our study. However, some diastolic blood pressure in $4^{\text {th }}, 6^{\text {th }}$, and researchers stated that cardiovascular $8^{\text {th }}$ weeks (i.e., 2 months). This is in exercise should be performed aerobic accordance with Hagberg ${ }^{(19)}$ who stated exercise for 30 -60 minutes, at least three that blood pressure reductions typically times a week. Patient may divide his/her appeared within 3 months of the start of training, \& further reduction did not occur after that. However, this was not in agreement with Montain et al.,(20) who found that improvements in systolic \& diastolic blood pressure in first 3 months of exercise training increased further with additional 6 months of exercise training. Generally, when exercise was discontinued, blood pressure rose again.

Regarding duration of exercise, many researchers recommended that duration session into three 10 minute stretches. ${ }^{(21)}$ In relation to frequency of walking exercise per week, the present findings showed that walking three times a week produced significant reduction of blood pressure. This was in accordance with the finding of Georgiades, et al.,(22) and Franklin \& Wappes ${ }^{(23)}$ who found that aerobic exercise performed 3 times a week was enough to reduce a systolic \& diastolic blood pressure. However(22,23), this was not in agreement with Halbert JA et al.,(12) who stated that a frequency of 
three exercise sessions per week has often, it's just easier to write a been considered to be the minimal prescription and toss the patient a frequency for blood pressure reduction \& handout on "Managing Hypertension" or each subject should participate in a "Managing Cholesterol" or the like.(2)

minimum of 30 minutes at least 5 days a Aerobic exercise is associated with a week significant reduction of blood pressure in

In the current study, the significant hypertensive and normotensive improvement for both systolic and participants and in overweight, as well as diastolic blood pressure were observed normal-weight participants. ${ }^{(18)}$

in the experimental group (GI) who

It was found that there was a was on walking exercise program and followed the prescribed drugs. This result was not in agreement with Niedfeldt and Click et al.,(24,25) who revealed that some antihypertensive drugs can impair the ability to exercise or alter the body's response to exercise.

The sad fact is that most physicians don't have discussed the benefits of aerobic exercise with their patients. ${ }^{(26)}$ Managed care limits the amount of time physicians spend with each patient and, statistical significant difference between group I and group II regarding the benefits of walking program exercises on SBP and DBP, on $4^{\text {th }}, 6^{\text {th }}$, and $8^{\text {th }}$ weeks in relation to systolic and diastolic blood pressure $(p$ value $=0.009,0.024$, and 0.002), respectively. This was in agreement with Whelton et al.,(18) \& Hagberg(19) who reported that aerobic exercises lowered BP of hypertensive patients. The average drop in blood pressure was $3.9 / 2.6 \mathrm{mmHg} .^{(18,27,28)}$ The scientific rationale for exercise 
in hypertension is largely built on considered as a new life style. This population studies. Cross-sectional findings was supported by Hillman and studies have been shown that blood Kravit.(4) they found that chronic pressure to be significantly lower in adaptations are derived from the active individuals than in their accumulation of several continuous sedentary peers. In one survey of 1,700 exercise bouts over a period of time.

men, those who had the least estimated

At the end of the study, aerobic energy expenditure had the highest exercise program lowered both systolic mean blood pressure, while the most and diastolic BP. Also the type of aerobic active men had the lowest mean. ${ }^{(17,29)}$ exercise is largely a matter of patient This result is in agreement with our preference. Walking at a 15-minutes/mile study, which showed that blood pace is ideal for many-it requires no pressure was significantly lower in equipment or special clothing and fits group I (active subjects) than in group II (sedentary subjects).

readily into most patients' schedules. Some prefer jogging, biking, or

In the present study, the experimental swimming. Exercise machines such as group of subjects was asked to monitor treadmills, stationary cycles, or crosstheir comfort during each walking country ski devices provide an effective session. It was observed that the minority workout for individuals who enjoy of the studied subjects feel some exercising at home, at a health club, or discomfort during walking, because gym walking exercise is not a common CONCLUSION practice among Egyptian people and is The results of the study strongly 
support the beneficial effect of aerobic regular exercise in reducting both of systolic \& diastolic blood pressure and heart rate in hypertensive patients. It is interesting that the effects of a graded walking exercise program on hypertension add up. If patient exercises moderately three times a week, within four weeks, regular aerobic exercise can lower blood pressure readings and by the time pressure starts resuming its target level.

\section{RECOMMENDATIONS}

Special attention should be paid to aerobic exercise for hypertensive patients.

patients and should be integral program.

component of hypertension education

Booklets with simple instructions and diagrams about aerobic exercise as regard benefits, types, duration, and frequency can be used as a teaching aids for hypertensive patients in all outpatient clinics.

Educational campaign emphasizing the benefits of aerobic exercise in reduction of both systolic and diastolic blood pressure.

Further study to identify the effect of duration and frequency of aerobic exercise program in hypertensive 
Table 1: Characteristics of the studied sample

\begin{tabular}{|c|c|c|c|c|c|}
\hline & \multicolumn{2}{|c|}{ GI } & \multicolumn{2}{|c|}{ Gll } & \multirow{2}{*}{$\begin{array}{c}\text { Sign. Test } \\
X^{2}=1.026 P=(0.3112\end{array}$} \\
\hline & No. & $\%$ & No. & $\%$ & \\
\hline \multicolumn{6}{|l|}{ Sex } \\
\hline Male & 1 & 5 & 0 & 0.0 & \\
\hline Female & 19 & 95 & 20 & 100 & \\
\hline Age & \multirow{2}{*}{\multicolumn{2}{|c|}{$\begin{array}{c}30-60 \\
48.60 \pm \\
8.45\end{array}$}} & \multirow{2}{*}{\multicolumn{2}{|c|}{$\begin{array}{c}34-66 \\
49.25 \pm \\
9.68\end{array}$}} & \\
\hline $\begin{array}{l}\text { Min- Max } \\
\text { Mean + SD }\end{array}$ & & & & & $\begin{array}{c}t=0.23 \\
p=(0.822)\end{array}$ \\
\hline \multicolumn{6}{|l|}{ Education } \\
\hline Illiterate & 16 & 80 & 18 & 90 & $x^{2}=1.318 p=(0.5175)$ \\
\hline Read \& write & 4 & 20 & 2 & 10 & \\
\hline \multicolumn{6}{|l|}{ Socio-economic status } \\
\hline Low & 20 & 100 & 19 & 95 & $x^{2}=1.026 p=(3112)$ \\
\hline Moderate & 0 & 0 & 1 & 5 & \\
\hline \multicolumn{6}{|l|}{ Marital status } \\
\hline Married & 16 & 80 & 16 & 80 & $x^{2}=0.000 p=(1.000)$ \\
\hline Widowed & 4 & 20 & 4 & 20 & \\
\hline
\end{tabular}

* Significant $\mathrm{P}<0.05$

Gl: Experimental group

Gll: Control group 
Table 2: The studied sample compliance to their therapeutic regimen

\begin{tabular}{|c|c|c|c|c|c|}
\hline & \multicolumn{2}{|l|}{ GI } & \multicolumn{2}{|l|}{ GII } & \multirow{2}{*}{$\begin{array}{l}\text { Sign. Test } \\
t=1.71 \\
p=(0.095)\end{array}$} \\
\hline & No. & $\%$ & No. & $\%$ & \\
\hline Duration of drug intake & \multirow{3}{*}{\multicolumn{2}{|c|}{$\begin{array}{l}0.80-12 \\
4.39 \pm 2.89\end{array}$}} & \multirow{3}{*}{\multicolumn{2}{|c|}{$\begin{array}{l}1-20 \\
7.53 \pm 7.65 \\
\end{array}$}} & \\
\hline Min - Max (year) & & & & & \\
\hline Mean $\pm S D$ & & & & & \\
\hline $\begin{array}{l}\text { Drugs used } \\
\text { Single drug } \\
\text { Combination }\end{array}$ & $\begin{array}{l}15 \\
5\end{array}$ & $\begin{array}{l}75 \\
25\end{array}$ & $\begin{array}{l}8 \\
12\end{array}$ & $\begin{array}{l}40 \\
60\end{array}$ & $\begin{array}{l}x^{2}=5.01^{*} \\
p=(0.01)\end{array}$ \\
\hline $\begin{array}{l}\text { Lower dietary salt } \\
\text { Yes } \\
\text { No }\end{array}$ & $\begin{array}{l}14 \\
6\end{array}$ & $\begin{array}{l}70 \\
30\end{array}$ & $\begin{array}{l}14 \\
6\end{array}$ & $\begin{array}{l}70 \\
30\end{array}$ & $\begin{array}{l}x^{2}=0.0 \\
p=(1.000)\end{array}$ \\
\hline $\begin{array}{l}\text { Lower dietary fat } \\
\text { Yes } \\
\text { No }\end{array}$ & $\begin{array}{l}14 \\
6\end{array}$ & $\begin{array}{l}70 \\
30\end{array}$ & $\begin{array}{l}12 \\
8\end{array}$ & $\begin{array}{l}60 \\
40\end{array}$ & $x^{2}=0.4395 p=(0.5073)$ \\
\hline $\begin{array}{l}\text { Echo findings } \\
\text { Normal } \\
\text { Abnormal }\end{array}$ & $\begin{array}{l}7 \\
13\end{array}$ & $\begin{array}{l}35 \\
65\end{array}$ & $\begin{array}{l}6 \\
14\end{array}$ & $\begin{array}{l}30 \\
70\end{array}$ & $\begin{array}{l}X^{2}=0.11396 \\
p=(0.736)\end{array}$ \\
\hline
\end{tabular}

* Significant $P<0.05$ 
Table 3: Differences between experimental group and control group for follow up parameters' assessment before and after walking program exercises

\begin{tabular}{||l|l|l|l|l|l||}
\hline Variables & Base line & $\mathbf{2}^{\text {nd }}$ Week & $\mathbf{4}^{\text {th }}$ Week & $\mathbf{6}^{\text {th }}$ Week & $\mathbf{8}^{\text {th }}$ Week \\
\hline Weight & & & & & \\
Group I & $79.45 \pm 9.45$ & $80.03 \pm 9.51$ & $79.28 \pm 9.69$ & $78.65 \pm 9.63$ & $78.15 \pm 9.68$ \\
Group II & $79.72 \pm 10.63$ & $80.10 \pm 10.56$ & $80.27 \pm 10.67$ & $80.53 \pm 10.74$ & $80.70 \pm 10.68$ \\
\hline Test (t) & $\mathbf{0 . 0 9}$ & $\mathbf{0 . 0 2}$ & $\mathbf{0 . 3 1}$ & $\mathbf{0 . 5 8}$ & $\mathbf{0 . 9 7}$ \\
P & $\mathbf{0 . 9 3 2}$ & $\mathbf{0 . 9 8 1}$ & $\mathbf{0 . 7 5 8}$ & $\mathbf{0 . 6 5 6}$ & $\mathbf{0 . 4 3 4}$ \\
\hline BMI & & & & & \\
Group I & $31.56 \pm 4.41$ & $31.79 \pm 4.45$ & $31.50 \pm 4.51$ & $31.25 \pm 4.45$ & $31.05 \pm 4.48$ \\
Group II & $31.05 \pm 3.10$ & $31.19 \pm 3.04$ & $31.26 \pm 3.08$ & $31.36 \pm 3.10$ & $31.43 \pm 3.10$ \\
\hline Test (t) & $\mathbf{0 . 4 3}$ & $\mathbf{0 . 5 0}$ & $\mathbf{0 . 1 9}$ & $\mathbf{- 0 . 0 9}$ & $\mathbf{- 0 3 1}$ \\
P & $\mathbf{0 . 6 7 1}$ & $\mathbf{0 . 6 2 1}$ & $\mathbf{0 . 8 4 8}$ & $\mathbf{0 . 9 2 7}$ & $\mathbf{0 . 7 5 6}$ \\
\hline HR & & & & & \\
Group I & $83.45 \pm 5.65$ & $80.75 \pm 3.67$ & $79.65 \pm 2.43$ & $79.50 \pm 2.91$ & $79.10 \pm 2.05$ \\
Group II & $88.00 \pm 10.25$ & $84.50 \pm 7.41$ & $87.20 \pm 7.80$ & $86.20 \pm 9.53$ & $90.40 \pm 11.25$ \\
\hline Test (t) & $\mathbf{- 1 . 7 4}$ & $\mathbf{- 2 . 0 3}$ & $-4.13^{\star}$ & $\mathbf{- 3 . 0 1 ^ { * }}$ & $\mathbf{- 4 . 4 2 ^ { * }}$ \\
P & $\mathbf{0 . 0 9 0}$ & $\mathbf{0 . 0 5 2}$ & $\mathbf{0 . 0 0}$ & $\mathbf{0 . 0 0 5}$ & $\mathbf{0 . 0 0}$ \\
\hline SBP & & & & & \\
Group I & $155.25 \pm 12.08$ & $149.75 \pm 11.29$ & $140.75 \pm 7.66$ & $136.00 \pm 6.20$ & $127.50 \pm 6.39$ \\
Group II & $154.00 \pm 14.29$ & $145.50 \pm 12.76$ & $154.50 \pm 13.95$ & $146.00 \pm 13.92$ & $151.50 \pm 13.09$ \\
\hline Test (t) & $\mathbf{0 . 3 0}$ & $\mathbf{1 . 1 2}$ & $\mathbf{- 3 . 8 7 ^ { \star }}$ & $\mathbf{- 2 . 9 4 ^ { \star }}$ & $\mathbf{- 7 . 3 7 ^ { * }}$ \\
P & $\mathbf{0 . 7 6 7}$ & $\mathbf{0 . 2 7 2}$ & $\mathbf{0 . 0 0 0}$ & $\mathbf{0 . 0 0 6}$ & $\mathbf{0 . 0 0}$ \\
\hline DBP & & & & & \\
Group I & $91.00 \pm 8.37$ & $90.50 \pm 7.24$ & $88.00 \pm 5.94$ & $84.50 \pm 8.26$ & $81.50 \pm 6.71$ \\
Group II & $91.50 \pm 8.13$ & $88.25 \pm 8.78$ & $93.50 \pm 6.71$ & $90.00 \pm 6.49$ & $89.50 \pm 8.26$ \\
\hline Test (t) & $-\mathbf{0 . 1 9}$ & $\mathbf{0 . 8 8}$ & $\mathbf{- 2 . 7 5}$ & $\mathbf{- 2 . 3 4 ^ { \star }}$ & $\mathbf{- 3 . 3 6 ^ { \star }}$ \\
P & $\mathbf{0 . 8 4 9}$ & $\mathbf{0 . 3 8 2}$ & $\mathbf{0 . 0 0 9}$ & $\mathbf{0 . 0 2 4}$ & $\mathbf{0 . 0 0 2}$ \\
\hline
\end{tabular}

* Significant $\mathrm{P}<0.05$

BMI: Basal metabolic index DBP: Diastolic blood pressure

SBP: systolic blood pressure HR: heart rate 
Table 4: The patient's comfort as regard the duration spent on each walking session by group I.

\begin{tabular}{||c|c|c|c|c|c|c|c|c||}
\hline \multirow{2}{*}{ Patient's comfort } & \multicolumn{2}{|c|}{$10 \mathrm{~min}$} & \multicolumn{2}{c||}{$20 \mathrm{~min}$} & \multicolumn{2}{c||}{$30 \mathrm{~min}$} & \multicolumn{2}{c||}{40 min } \\
\cline { 2 - 9 } & No. & $\%$ & No. & $\%$ & No. & $\%$ & No. & $\%$ \\
\hline Comfort & 20 & 100 & 18 & 90 & 16 & 80 & 12 & 75 \\
\hline Discomfort & 0 & 0 & 2 & 10 & 4 & 20 & 5 & 25 \\
\hline
\end{tabular}

\section{REFERENCES}

1. Fang J, Wylie-Rosett, J, Alderman $\mathrm{MH}$. Exercise and cardiovascular outcomes by hypertensive status: NHANES I epidemiological follow-up study. American Journal of Hypertension. 2005; 18, 751-8

2. Reents $S$. Exercise and Hypertension - A reviewer at Athlete. Medicine \& Science in Sports \& Exercise. 2004; 36: 33-43.

3. Ibrahim M, Rizk H, AppelLJ, Helmy S, Ashour Z. Hypertension, prevalence, awareness, treatment and control in Egypt. Results from the Egyptian National Hypertension Project (NHP) investigative team. Hypertension.Dec.1995; 26 (6 pt 1): 886-90.

4. Hillman,G, Kravit Z. Hypertension and Exercise. Hypertension. 2001;36:161-5
5. Onusko E. Diagnosing Secondary Hypertension. American Family Physician. 2003; 67 (1): 67-9.

6. Pescatello LS, Franklin BA, Fagard R, Farquhar WB, Kelley GA, Ray CA. Exercise and hypertension. Medicine \& Science in Sports \& Exercise. 2004; 36 (3): 533-53.

7. McManus $R$, Mant J, Roalfe A, Oakes R, Bryan S. Targets and self monitoring in hypertension : randomized controlled trial and cost effectiveness analysis. British Medical Journal Middle East. 2005; $12(1): 55-7$.

8. Hegazy A, Abdel Kader B. Clinical significance of impaired heart rate recovery after treadmill exercise test in hypertensive patients. Kuwait Medical Journal. 2004; 36 (1): 19-24.

9. Kaplan NM. Cardiovascular risk reduction: the role of 
antihypertensive

treatment.

American Journal of Medicine.. 1991; 90(suppl. 2A): 19-20.

10. American College of Sports Medicine. Exercise your way to lower blood pressure. 2001.

11. Wallace JP. Exercise in hypertension. Sports Medicine. 2003; 33 (8), 585- 98.

12. Halbert JA, Silagy CA, Finucane $P$. The effectiveness of exercise training in lowering blood pressure: a meta-analysis of randomised controlled trials of 4 weeks or longer. J Hum Hypertens. 1997; 11: 641-9.

13. Hinderliter $A$, et al.. Reduction of left ventricular hypertrophy after exercise and weight loss in overweight patients with mild hypertension. Arch Intern Med. 2002; 162: 1333-9.

14. Tsai JC, et al. The beneficial effect of regular endurance exercise training on blood pressure and quality of life in patients with hypertension. Clin Exp Hypertens. 2004; 26: 255-65.

15. Roberts CK, et al. Effect of diet and exercise intervention on blood pressure, insulin, oxidative stress, and nitric oxide availability. Circulation. 2002; 106: 2530-2.

16. Cornelissen V, Fagard R.. Effects of endurance training on blood pressure, blood pressure-regulating mechanisms, and cardiovascular risk factors. Hypertension. 2005; 46, 66775.

17. Bove AA, Sherman C. Low pressure workouts for hypertension. The physician \& sports Medicine. 1998; 26 (4). 1-7

18. Whelton SP, et al. Effect of aerobic exercise on blood pressure: a metaanalysis of randomized, controlled trials. Ann Intern Med. 2002; 136: 493-503.

19. Hagberg JM. Exercise, fitness, and hypertension. In: Bouchard C, Shephard RJ, Stephens T, et al: Exercise, Fitness, and Health: A Consensus of Current Knowledge, Champaign, IL: Human Kinetics Books; 1990. pp 455-466

20. Montain SJ, Martin WH III, Hagberg $\mathrm{JM}$, et al: Effect of exercise training on 60- to 69-year-old persons with essential hypertension. Am J Cardiol. 1989. 64(5):348-53

21. High blood pressure and Exercise. Htm. MedicWeb - Hypertension Info Site

22. Georgiades A, Sherwood A, Gullette $E C$, et al. Effects of exercise and weight loss on mental stress-induced cardiovascular responses in individuals with high blood pressure. Hypertension. 2000; 36:171-6

23. Franklin BA, Wappes JR. Taking the Pressure: How Exercise Can Lower High Blood Pressure. The Physician and Sportsmedicine. 1996.24(6)1-3.

24. Niedfeldt MW. Managing in Athletes and Physically Active Patients. American Family Physician. 2002;66(3).1-13.

25. Chick TW, Halperin AK, Gacek EM. The effect of antihypertensive medications on exercise performance: a review. Med Sci Sports Exerc. 1988;20:447-54

26. Ma J, Urizar GG, Alehegn T, et al. Diet and physical activity counseling during ambulatory care visits in the United States. Prev Med. 2004; 39:815-22.

27. Hagberg JM. The Role of Exercise training in the treatment of 
hypertension. Sports Medicine. 2000;30(3) 193 -206.

28.Kokkinos P, Pittaras A, Coutoulakis E, Colleran J, Narayan P, Dotson C, et al. Determinants of exercise blood pressure in normotensive and hypertensive women: role of cardiorespiratory fitness. J Cardiopulm Rehabil. 2002. 22: 17883.

29. Montoye HJ, Metzner HL, Keller JB, et al: Habitual physical activity and blood pressure. Med Sci Sports. 1972;4(4):175-81 